\title{
PENDIDIKAN MASA KINI UNTUK GENERASI PENERUS PERJUANGAN NABI MUHAMMAD SAW.
}

\author{
Mihmidaty Ya'cub \\ UIN Sunan Ampel Surabaya \\ Email: mihmidaty@gmail.com
}

Abstrak:

To be able to realize the next generation of the Prophet's struggle, professional Islamic teachers are needed, namely teachers who are able to educate their students to become the next generation of the Prophet's struggle. It also requires the ability of teachers to use varied learning methods, productive learning strategies and modern educational media. It is also necessary to provide adequate infrastructure that can support teachers in carrying out the teaching and learning process well and attract students' interest. By knowing the characteristics of this millennial generation, the world of education can play a role and adjust learning strategies in such a way as to bring this millennial generation to an optimal level of success.

Keyword: Education Present, Successor of Prophet Muhammad

\section{Pendahuluan}

Para Nabi dan Rosul diutus oleh Allah pada kaum tertentu, misalnya Nabi Musa, Nabi Isa untuk Bani Israel, Nabi Nuh, Nabu Hud untuk kaum 'Ad. Nabi Shaleh untuk Kaum Tsamud,. Tetapi hanya Nabi Muhammad saw. diutus oleh Allah untuk membimbing seluruh ummat manusia di bumi, Para Nabi dan Rasul sebelum Nabi Muhammad, diutus menyampaikan risalah pada waktu sebatas usianya saja, Ketika sudah wafat, maka selesai tugas kenabiyan dan kerasulannya. Akan tetapi untuk Nabi Muhammad tidak demikian. Karena sudah tidak diutus Nabi setelah Nabi Muhammad saw, maka syariatnya sudah disetting oleh Allah berlaku sepanjang zaman. Setelah wafat, syariatnya tetap berlaku..Untuk ini, maka perlu secara terus menerus mendidik generasi penerus perjuangan Nabi Muhammad saw.mencetak kader ulama' pewaris Nabi yang ahli dalam membimbing ummat, jika urusan diserahkan kepada yang bukan ahlinya, maka akan menemui kehancuran, sebagaimana sabda Nabi:

$$
\text { اذاوسد الامر الى غير اهله فانظظر الساعة }
$$


Artinya: Jika urusan diserahkan pada orang yang bukan ahlinya, maka tunggu saat kehancurannya. ${ }^{1}$ Hal-hal yang berkaitan dengan agama merupakan urusan yang sangat penting. Jika dilaksanakan oleh orang yang bukan ahlinya, maka akan terjadi sesat dan menyesatkan. Untuk ini maka diperlukan perndidikan yang mencetak generasi penerus Nabi.

Generasi penerus perjuangan Nabi adalah orang-orang yang telah dipilih oleh Allah, sebagaimana ayat tersebut diatas, orang-orang pada tingkatan pertama, yang difahamkan oleh Allah tentang ilmu-ilmu hukum Islam: sebagaimana sabda Nabi:

$$
\text { من يرد الله به خيرا يفقهه فى الدين }
$$

Artinya: Orang yang dikehendaki oleh Allah menjadi orang baik, maka orang tersebut difahamkan oleh Allah tentang Agama Islam / hukum-hukum Islam. ${ }^{2}$

Selain tersebut diatas, Nabi juga bersabda yang meruju' pada sifat generasi penerus perjuangan Nabi:

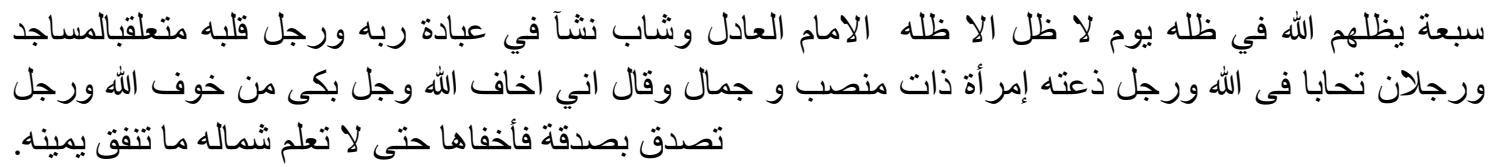

Artinya: Ada tujuh golongan yang dinaungi oleh Allah di hari tidak ada naungan kecuali naungan Allah (harikiyamat). 1. Imam yang adil. 2.Pemuda yang tumbuh dengan rajin ibadah pada Allah. 3. Orang yang hatinya selalu berhubungan dengan masjid. 4. Oring yang saling menyintai karena Allah. 5. Orang yang dirayu wanita yang cantik punya kedudukan, tetapi dia menjawab saya takut Allah. 6. Orang yang menangis karena takut Allah. 7. Orang sedekah yang dirahasiakan sehingga tangan kirinya tidak tahu apa yang dibelanjakan oleh tangan kanannya. ${ }^{3}$

Generasi penerus perjuangan Nabi ini yang sekarang sedang dalam proses pendidikan adalah generasi milenial, adalah generasi yang lahir setelah tahun 1980, dengan karekteristik antara lain 1. Lebih mementingkan pengalaman pribadi atau sharing dari komunitasnya, 2.. Selalu memerlukan internet untuk media sosialnya berupa Facebook, WhatsApp, Instagram, Twitter dan lain-lain. 3. Serba digital dan online untuk mendapatkan informasi yang tak terbatas maupun untuk keperluan yang lain. ${ }^{4}$ 4. Memiliki sifat optimis. 5. Independent. 6.. Terobsesi oleh kesuksesan. g. Percaya diri. h.Mementingkan gaya hidup.. 8. Tergantung oleh teknologi. ${ }^{5}$ 9. Lebih terbuka dan bertoleransi terhadap perubahan. ${ }^{6}$

${ }^{1}$ Imam Abu Dawud, Sunan Abu Dawud, 605.

2 Imam Bukhari, Shahih Bukharijilid I, Beirut: Dar al Kutub al Ilmiyah, 2000), 134.

${ }^{3}$ Ibnu Hajar al ‘Asqolani, Bulughul Maram,( Makkah: al Haramain. 1378 H), 132.

4 Winastiti, A. (2016), Generasi Milenial dan Karekteristiknya, CNN Indonesia.https//student.cnnindonesia.com.

${ }^{5}$ Rinandiyana, Kurniawati dan Kurniawan, (2017), Analisis Factor-faktor yang Mempengaruhi Keputusan Pembelian oleh Generasi Milenial,Jurnal Ekonomi Manajemen. Volume 3, nomor 1. 
Dengan mengetahui karakteristik generasi milenial ini, maka dunia pendidikan dapat memainkan peran dan menyesuaikan strategi pembelajaran sedemikian rupa untuk membawa generasi milenial ini pada tingkat keberhasilan yang optimal. Dalam hal ini adalah untuk mencetak manusia yang dipilih oleh Allah sebagai generasi penerus perjuangan Nab sebagaimana dalam ayat tersebut di atas..

\section{Pembahasan.}

\section{Pendidikan Masa Kini.}

\section{a. Guru Profesional.}

Dalam melaksanakan tugas mendidik dan mengajar, seorang guru dituntut menjadi guru yang professional. Guru Profesional adalah Guru yang mampu mendidik muridnya menjadi generasi yang mampu bersaing dan memiliki moral yang baik. Guru Profesional harus mempunyai empat kompetensi yang sudah ditetapkan dalam Undang Undang Republik Indonesia nomor 14 tahun 2005 mengenai Guru dan Dosen. Empat kompetensi dasar tersebut adalah pertama kompetensi paedagogik, kedua kepribadian, ketiga profrsional dan keempat sosial. Selain terampil dalam melakukan pengajaran, juga harus mempunyai kemampuan ilmu pengetahuan yang luas, bijak dalam bertindak dan juga mampu untuk bersusialisasi dengan baik. Allah juga memerintahkan agar setiap orang berkarya sesuai dengan profesinya:

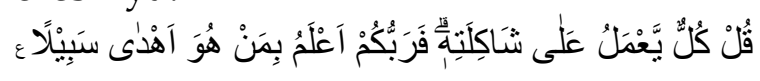

Artinya: Katakanlah (Muhammad), "Setiap orang berbuat sesuai dengan profesinya masing-masing." Maka Tuhanmu lebih mengetahui siapa yang lebih benar jalannya. ${ }^{7}$

Segala sesuatu yang dilaksanakan oleh ahlinya atau sesuai dengan profesinya, maka akan dapat mencapai hasil yang optimal. Demikian juga dalam pekerjaan sebagai guru. Kriteria atau ciri-ciri guru professional adalah sebagai berikut: menguasai kurikulum Pendidikan, menguasai materi yang diajarkan, terampil menggunakan multi metode pembelajaran, memiliki kedisiplinan dalam arti luas, berakhlakul karimah ( akhlak yang mulia ), mampu mendidik dan mengajar. mempunyai kualifikasi akademik, mampu berkomunikasi dengan baik, menguasai administrasi Pendidikan, memiliki semangat pengabdian yang tinggi, terus belajar, aktif, kreatif dan inovatif, selalu up to date informasi, menguasai ilmu pengetahuan dan

\footnotetext{
${ }^{6}$ Panjaitan dan Prasetya, (2017), Pengaruh Sosial Media Terhadap Produktivitas Kerja Generasi Millenial, Jurnal Administrasi Bisnis, Volume 48, Nomor 1.

${ }^{7}$ Al Quran, 17 ( Al Isra' ), 84.
} 
teknologi/ IT, akktif dalam aktifitas organisasi kependidikan, memiliki sikap cinta kasih, ikhlas mengajar.

Guru professional, selain memiliki empat kempetensi dan lima belas kriteria diatas, yang tidak kalah pentingnya adalah dapat menerapkan multi metode mengajar, melaksanakan strategi pembelajaran produktif dan menggunakan media pembelajaran dengan baik.

\section{b. Metode, Strategi dan Media Pembelajaran.}

\section{1) Metode Pembelajaran}

Dalam proses belajar mengajar, guru dituntut kemampuan untuk mengkolaborasikan beberapa metode yang sesuai dengan pokok bahasan. Tidak cukup mengajar dengan menggunakan satu metode saja. Guru harus bisa memilih dan menyesuaikan beberapa metode pembelajaran selama proses belajar mengajar berlangsung.

Metode mengajar pada hakikatnya adalah cara menyampaikan ilmu dari guru kepada murid. Terdapat banyak metode mengajar, antara lain : a. Metode ceramah, b. Metode diskusi, c. Metode demonstrasi. d. Metode resitasi. e. Metode percobaan atau experiment. f. Metode karya wisata. g. Metode latihan ketrampilan. h. Metode pemecahan masalah. i. Metode discoveri.(mencari jawaban dari pertanyaannya sendiri. j. Metode inquiry (menemukan/ mengalami semdiri). k. Mind Mapping ( berfikir runtun terhadap suatu masalah). 1. Metode Role Playing (bernagi peran). m. Metode cooperative script (berpasangan mengutarakan intisari materi).n. Metode debat,

\section{2) Strategi Pembelajaran.}

Selain bisa mengkolaborasikan metode pembelajaran dengan baik, Guru professional juga dapat menerapkan strategi pembelajaran. Yaitu strategi pembelajaran produktif. Antara lain adalah CBSA Cara Belajar Siswa Aktif, Quantum Teaching and Lerning, CTL Contextual Teaching and Learning dan lain-lain. Yng akan diuraikan di sini adalah CTL. yang dimaksud adalah: Konsep belajar yang membantu guru mengaitkan materi yang diajarkannya dengan situasi dunia nyata siswa dan mendorong siswa membuat hubungan antara pengetahuanyang dimilikinya dengan penerapan dalam kehidupan sehari-hari. ${ }^{8}$

Contextual Teaching and Learning mempunyai tujuh komponen yaitu pertama Constructive bahwa ilmu pengetahuan dibangun sedikit demi

${ }^{8}$ Nurhadi, Pendekatan Kontekstual (Contextual Teaching and Lerning/ CTL), (Malang:Universitas Negeri Malang, 2004), 5 . 
sedikit dari yang termudah. ${ }^{9}$ Kedua: Questioning adalah bertanya, bahwa salah satu faktor pendorong seseorang belajar adalah sifat ingin tahu,sebagai modal dasar untuk bersikap peka, kritis, mandiri dan kreatif; maka kegiatan belajar mengajar perlu memperhatikan rasa ingin tahu agar bermakna bagi siswa. ${ }^{10}$

Ketiga Inquiry atau menemukan sendiri. Pengetahuan dan ketrampilan yang diperoleh siswa dengan menemukan atau mengalami sendiri. Guru harus merancang kegiatan yang mengarah pada kegiatan menemukan materi apapun yang diajarkan. ${ }^{11}$ Keempat Learning community atau masyarakat belajar. Disarankan agar hasil pembelajaran diperoleh dari kerjasama dengan orang lain. Biasanya dalam bentuk kelompok. Hal ini dapat mendorong siswa berfikir kritis, menyampaikan pendapat secara bebas yang dapat mengembangkan daya pikir dan kepekaan terhadap situasi kehidupan dimana dia berada. ${ }^{12}$

Kelima: Modeling atau pemodelan. Belajar denga ada model yang ditiru dan diamati oleh siswa. Yang menjadi model adalah guru dan seluruh siswa. Keenam Reflection atau tanggapan spontan setelah belajar untuk menerapkannya. Ketujuh Authentic Assesment atau penilaian sebenarnya. Adalah penilaian yang dilaksanakan selama proses pembelajaran berlangsung, bukan hanya pada test akhir. ${ }^{13}$

Semua materi pembelajaran Aqidah Ibadah dan Akhlaq selalu mengacu pada pelaksanaan dalam kehidupan nyata dengan melalui proses tujuh komponen tersebut diatas. . Sebagai contoh pelajaran Aqidah: Allah maha melihat, maha mendengan dan maha tahu, dalam kehidupan nyata, siswa tidak berani melanggar hukum Allah karena merasa dilihat Allah, diketahui Allah dan didengarkan Allah, bukan sebaliknya.

\section{3) Media Pembelajaran.}

Media pembelajaran adalah sesuatu yang digunakan oleh pendidik untuk meningkatkan kemauan siswa mengikuti proses belajar mengajar. Atau sesuatu yang digunakan oleh guru untuk menghantarkan anak

\footnotetext{
${ }_{9}^{9}$ Ali Imron, Balajar dan Pembelajaran, (Jakarta: Pusaka Jaya, 2000), 106.

10 Baltbang DepDikNas, Kurikulum Berbasis Kompetensi, Ringkasan KBM, (Jakarta: balitbang@cbn,net,id,2002), 4.

${ }_{11}$ DepDikNas, 4.

12 Muhibbin Syah, Psychologi Pendidikan dengan Pendekatan Baru, ( Bandung: PT. Remaja Rosdakarya, 2000), 205.

${ }_{13}$ Mihmidaty Ya'cub, Efektivitas Penerapan Contextual Teaching and Learning di Pondok Pesantren Hidayatullah, ( Surabaya: UIN Sunan Ampel Pres, 2014), 26.
} 
didik mudah memahami materi pelajaran. Sedangkan Media Pembelajaran Agama Islam adalah sesuatu yang digunakan untuk menyampaikan materi Pendidikan Islam kepada peserta didik dalam mewujudkan kepribadian seorang muslim.

Jenis-jenis media pembelajaran Agama Islam adalah a. Benda, seperti al Quran, Hadits, Buku-buku Tauhid, Fiqih, Akhlak, Sejarah dan lain-lain. b. Sumber daya alam, seperti manusia, tumbuh-tumbuhan, hewan .c. Gambar-gambar, grafik, d. Vidio, e. tape recorder, f. Media Sosial : You Tube, WhatsApp, Instgram, Twitter, Facebook dan lain-lain.

Manfaat penggunaan media pembelajaran.adalah a. Memperjelas materi pelajaran b. Membantu siswa untuk mempermudah pemahaman. c. Menjadikan pelajaran lebih menarik d. Melatih belajar dan menumbuhkan kemauan kerasnya untuk mempelajari sesuatu e. Membentuk kebiasaan anak dan melatih anak menyampaikan pendapat f. Membantu konsentrasi anak dalam memperhatikan dan menangkap pelaharan g.Meningkatkan ingatan h. Meningkatkan kemauan anak untuk belajar. ${ }^{14}$

\section{c. Sarana Prasarana..}

Sarana berarti alat yang langsung digunakan untuk mencapai tujuan pendidikan, misalnya ruang, buku, perpustakaan, laboratorium dan lain-lain. Sedangkan prasarana adalah alat yang tidak langsung untuk mencapai tujuan Pendidikan, misalnya: lokasi, bangunan sekolah, lapangan olahraga, uang dan lain-lain. Semua mata pelajaran memerlukan sarana pembelajaran, satu sama lain berbeda, untuk mendukung kinerja guru sehingga pembelajaran dapat berlangsung dengan menarik dan baik. Semakin lengkap dan memadai sarana pembelajaran yang dimiliki sekolah akan memudahkan guru dalam melaksanakan tugasnya sebagai tenaga Pendidikan.

Setiap Lembaga Pendidikan wajib memiliki sarana prasarana yang dibutuhkan, meliputi lahan, ruang kelas, ruang pimpinan, guru, tata usaha, ruang peroustakaan, tempat beribadah, tempat olahraga, kantin, kamar kecil, ruang bermain dan tempat lain yang diperlukan untuk menunjang proses pembelajaran.Dalam qoidah Fiqhiyah disebutkan :

$$
\text { ما لا يتم الو اجب الا به فهو واجب }
$$

${ }^{14} \mathrm{Ya}^{\prime} \mathrm{cub}, 30$ 
Artinya: Sesuatu yang dapat menyempurnakan sebuah kewajiban, maka sesuatu itu wajib hukumnya. 15

Sarana prasarana yang diperlukan dalam Pendidikan Agama Islam adalah masjid/ musholla dengan kamar mandi dan tempat wudlunya, sajadah, sarung, rukuh/ mukena, al Quran, pengeras suara, boneka besar dan alat praktek perawatan jenazah, perpustakaan, halaman untuk praktek penyembelihan hewan dan lain-lain yang dibutuhkan dalam pembelajaran.

\section{d. Materi Pendidikan Agama Islam.}

Materi Pendidikan Agama Islam merupakan bahan yang akan disajikan kepada peserta didik. Materi tersebut telah ditetapkan dalam kurikulum sekolah, yang menyesuaikan antara kurikulum nasional juga muatan lokal. Materi pembelajaran ini adalah sumber nurmatif Islam yang bersumber dari Al; Qur an dan Al Hadits dalam upayta mengembangkan kepribadian yang selaras dengan Al Qran dan Al Hadits. Kalau dalam rukun agama Islam itu ada tiga yaitu Iman Islam dan Ihsan. Iman dijabarkan pada ilmu Tauhid, ilmu kalam. Islam dijabarkan dalam Ilmu Fiqih, Qur an, Hadits, dan lain-lain. Ihsan dikembangkan dalam ilmu Tasawuf.

Ilmu Tauhid dan pengembangannya, Ilmu Fiqih dan pengembangannya sudah diajarkan di Lembaga Pendidikan Formal dari tingkat dasar sampai tingkat tinggi, namun ilmu tasawuf ini belum masuk dalam Kurikulum Pendidikan Agama Islam. Maka akibatnya, dunia Pendidikan menghasilkan manusia beragama yang formalitas saja. Kebanyakan materi Keislaman belum masuk kedalam relung hati yang paling dalam (hati nurani) yang senantiasa membimbing pada kebenaran. Untuk ini seharusnya materi Pendidikan Agama Islam atau Kurikulum Pendidikan Agama Islam ditambah dengan Ilmu Tasawuf yang bertujuan untuk membentuk manusia yang shalih, melaksanakan syariat Islam sebenar-benarnya, mensucikan jiwa, membersihkan hati, dan dekat dengan Allah. ${ }^{16}$

Secara khusus materi Pendidikan Agama Islam ini mengacu pada pembelajaran yang dilakukan oleh Luqman Hakim yang diabadikan oleh Allah dalam Quran surat Luqman:

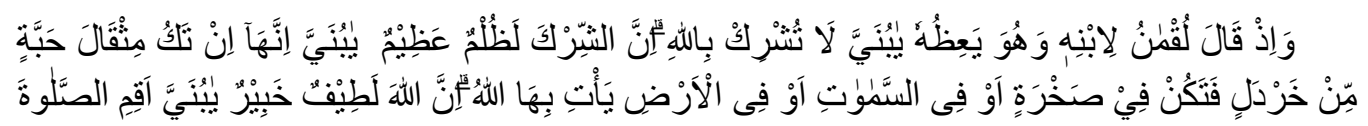

${ }^{15}$ Ibnu al Qoyyim, qo'idah Fiqhiyah,( Surabaya: al Hidayah, 2000), 19.

16 Ya'cub, Pendidikan Tasawuf dan Aplikasinya, 200. 


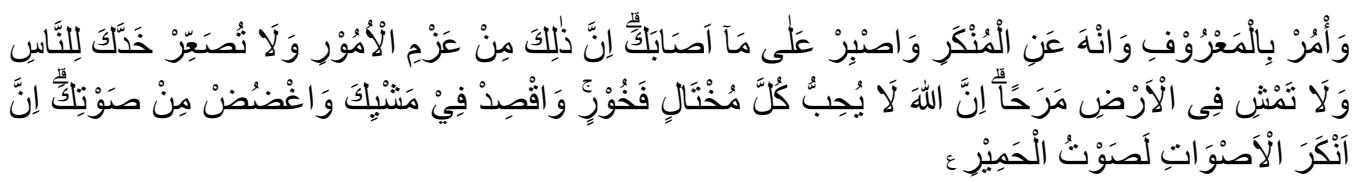

Artinya: 13. Dan (ingatlah) ketika Lukman berkata kepada anaknya, ketika dia memberi pelajaran kepadanya, "Wahai anakku! Janganlah engkau mempersekutukan Allah, sesungguhnya mempersekutukan (Allah) adalah benarbenar kezaliman yang besar." 16. (Lukman berkata), "Wahai anakku! Sungguh, jika ada (ses uatu perbuatan) seberat biji sawi, dan berada dalam batu atau di langit atau di bumi, niscaya Allah akan memberinya (balasan). Sesungguhnya Allah Mahahalus, Mahateliti. 17. Wahai anakku! Laksanakanlah salat dan suruhlah (manusia) berbuat yang makruf dan cegahlah (mereka) dari yang mungkar dan bersabarlah terhadap apa yang menimpamu, sesungguhnya yang demikian itu termasuk perkara yang penting.18. Dan janganlah kamu memalingkan wajah dari manusia (karena sombong) dan janganlah berjalan di bumi dengan angkuh. Sungguh, Allah tidak menyukai orang-orang yang sombong dan membanggakan diri"17

Pada ayat 13 menjelaskan tentang aqidah, hanya menyembah pada Allah saja. Ayat 16 masih memantapkan tentang Aqidah, bahwa semua amal perbuatan manusia sekecil apapun akan dibalas oleh Allah. Ayat 17 tentang materi ibadah dan tasawuf (ilmu yang menjernihkan hati), yaitu shalat, mengajak kebaikabn, mencegah kemungkaran dan sabar. Sedangkan ayat 18 tentang materi pembelajaran akhlak. Jadi materi Pendidikan Agama Islam meliputi Aqidah, Ibadah, Akhlak dan tasawwuf.

\section{e. Tujuan Pendidikan Islam.}

Tentang tujuan Pendidikan Agama Islam terdapat banyak pendapat, antara lain menurut Zuhairini, tujuan Pendidikan Agama Islam adalah membimbing anak agar menjadi orang muslim sejati, beriman teguh, beramal shalih, berakhlak mulia serta berguna bagi masyarakat, agama dan negara. ${ }^{18}$ Menurut Mohammad Dawud Ali, tujuan Pendidikan Agama Islam adalah membina insan yang beriman dan bertaqwa yang mengabdikan dirinya hanya kepada Allah, membina serta memelihara alam sesuai dengan Syariah serta memanfaatkannya sesuai dengan aqidah dan akhlak Islam. ${ }^{19}$ Sedangkan menurut Chabib Thoha: tujuan Pendidikan Agama Islam adalah meningkatkan keimanan, pemahaman, penghayatan dan pengalaman peserta didik tentang agama Islam sehingga menjadi manusia muslim yang beriman dan bertaqwa kepada Allah serta

17 AL Qur an, 31 (Luqman), 13, 16-19.

18 Zuhairini, et.al.Metodik Khusus Pendidikan Agama, ( Malang: Biro Ilmiyah Fakultas Tarbiyah IAIN Sunan Ampel, 1983), 45.

${ }^{19}$ Mohammad Daud Ali,Pendidikan Agama Islam, ( Jakarta: Raja Grafindo Persada, 1998), 181-182. 
berakhlak mulia dalam kehidupan pribadi, bermasyarakat, berbangsa dan bernegara. ${ }^{20}$ Pendapat lain tujuan Pendidikan Agama Islam adalah agar dapat menjadi insan kamil untuk mencapai kebahagiaan dunia dan akhirat, membentuk kepribadian yang sesuai dengan ajaran Agama Islam.

Dalam Al Quran, Allah berfirman yang meruju' pada tujuan Pendidikan:

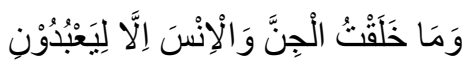

Artinya: Aku tidak menciptakan jin dan manusia melainkan agar mereka beribadah kepada-Ku. ${ }^{21}$

Dalam ayat ini menjelaskan bahwa tujuan Allah menciptakan manusia adalah agar menghamba pada Allah saja. Maka semua aktifitas manusia, termasuk Pendidikan diarahkan untuk mencetak manusia yang menghamba kepada Allah. Dari berbagai pendapat tentang tujuan Pendidikan Islam tersebut, dapat disimpulkan bahwa tujuan Pendidikan Agama Islam adalah agar peserta didik menjadi muslim sejati yang memiliki pengetahuan luas, nilai, sikap, tingkah laku yang sesuai dengan tuntutan syariat Islam, bermanfaat bagi mesyarakat, bangsa, negara dan agama yang mendapat ridlo Allah.

Tujuan Pendidikan Agama Islam ini sudah selaras dengan pembentuknya generasi penerus perjuangan Nabi Muhammad saw. Yaitu mencetak manusia kualitas Agamanya handal, menghamba pada Allah , berakhlak mulia dan siap membimbing ummat

\section{Pendidikan Masa Kini untuk Penerus Perjuangan Nabi Muhammad SAW.}

Untuk mencetak generasi penerus perjuangan Nabi Muhammad saw. Generasi calon Ulama' yang siap melaksanakan tugas-tugas kenabian adalah merupakan tanggung jawab Pendidikan. Dalam hal ini adalah Pendidikan Agama Islam. Pada era global yang serba digital dan online yang tidak bisa terlepas dari internet dewasa ini, dunia Pendidikan Islam juga harus lebih canggih dalam proses belajar mengajar, menyesuaikan dengan tuntutan perkembangan revolusi industri 4.0 yang mana mesin-mesin pintar sudah saling bertukar informasi satu sama lain, berkomunikasi secara langsung ke seluruh system teknologi informasi secara online. ${ }^{22}$ Dan sekarang sudah memasuki

${ }^{20}$ Chabib Thoha dan Abdul Mu'ti, PBM PAI di Sekolah Eksistensi dan Proses Belajar Mengajar Pendidikan Agama Islam, ( Bandung: Pustaka Pelajar,1998), 179.

${ }^{21}$ Al Quran, 51 (Adz Dzariyat), 56.

22 Asep Saifuddin Chalim, Model Pendidikan dalam mengatasi Problema Masa Kini dan akan datang. (Surabaya: UIN Sunan Ampel, 2019), 42. 


\section{Mihmidaty Ya'cub}

Pendidikan Masa Kini Untuk Generasi...

revolusi industry 5.0 yang mana mesin-mesin industry ini sudah melekat pada diri manusia dalam memenuhi kebutuhan hidup setiap individu.

Peserta didik diajari untuk memperoleh ilmu pengetahuan, mengembangkan dan mempraktekkan melalui mesin-mesin pintar yang serba digital dan online ini. Nabi Muhammad saw. telah mengisyaratkan datangnya zaman ini dengan sabdanya:

$$
\text { علموا او لادكم بقدر عقولهم فانهم مخلوقون لزمان غبر زمانكم }
$$

Artinya: Ajarilah anak-anak kalian (ilmu pengetahuan) sesuai dengan perkembangan akal pikirannya, karena sesungguhnya mereka adalah makhluk yang diciptakan untuk hidup di zaman yang sudah bukan zaman kalian. ${ }^{23}$ Dan sabda Nabi:

\section{انتم اعلم بأمور دنياكم}

Artinya: Kamu sekalian lebih tahu tentang urusan dunia kalian.24

Pada dua Hadits diatas menunjukkan bahwa Agama Islam mengapresiasi segala bentuk kemajuan yang disesuaikan dengan ajaran Islam. Karena ajaran Islam membimbing masyarakat sepanjang zaman. Generasi penerusnya juga dipersiapkan untuk menghadapi kehidupan dengan segala perubahannya sepanjang zaman.

Maka Guru Agama Islam yang profesional dalam melaksanakan tugas mengajar akan selalu menyesuaikan dengan situasi perkembangan zaman modern serba digital, online yang selalu terkait dengan internet. Dengan menerapkan metode pembelajaran, strategi dan media pembelajaran yang dapat mengakses teknologi modern. Misalnya pelajaran Tafsir al Quran atau Hadits, dengan metode inquiry (siswa menemukan atau mengalami sendiri materi yg sedang dipelajari), siswa tidak harus menemukan materi-materi Tafsir al Quran dan Hadits itu diperpustakaan, akan tetapi siswa sudah bisa menemukan semua materinya secara luas dan menyeliruh dalam aplikasi $\mathrm{Al}$ Quran dan Hadits, guru tinggal memantapkan sisi nilai-nilai dan pengamalannya.

Demikian juga dalam materi pembelajaran, Guru professional harus bisa menyiapkannya sedemikian rupa sehingga penyajian materi pembelajaran menarik minat siswa sesuai dengan eranya dan tetap mengacu pada kurikulum Pendidikan Agama Islam dan bahkan bisa memasukkan kurikulum muatan lokal yang dibutuhkan dalam kehidupan masyarakat.

Pendidikan masa kini dibutuhkan guru yang professional, penggunaan metode yang bervariasi, strategi pembelajaran yang baik, media pembelajaran yang sesuai dengan tuntutan zaman modern, sarana prasarana

\footnotetext{
${ }^{23}$ Imam Muslim, Shahih Muslim, ( Beirut: Dar al Kutub, 2002), 453.

${ }^{24}$ Muslim, Shahih Muslim, 243.
} 
yang memadai, materi pembelajaran yang dibutuhkan masyarakat dan dunia kerja ( dalam bidang keagamaan). Ini semua dalam rangka untuk mencapai tujuan Pendidikan Agama Islam yaitu mencetak muslim sejati berpengetahuan luas, nilai, sikap, tingkah laku yang sesuai dengan tuntutan syariat Islam, bermanfaat bagi mesyarakat, bangsa , negara dan agama yang mendapat ridlo Allah. Dan inilah generasi penerus perjuangan Nabi Muhammad saw.

\section{Kesimpulan}

Perlu mencetak generasi penerus perjuangan Nabi Muhammad SAW, karena Nabi Muhammad diutus untuk seluruh ummat manusia di alam, yang syariatnya terus berlaku sampai akhir zaman. Dan Nabi Muhammad sebagai penutup Nabi, berarti sudah tidak ada penerus Nabi. Generasi penerus perjuangan Nabi Muhammad saw ini memiliki karakteristik sebagaimana yang diillustrasikan Allah dalam Quran surat al Furqan ayat 63-74 dan Ali Imran ayat 134-135. Tugas generasi penerus perjuangan Nabi Muhammad saw adalah meneruskan tugas Nabi Muhammad saw yaitu membacakan ayat-ayat Allah, mensucikan manusia, mengajari Qur an dan Hadits dan mengajari manusia pengetahuan agama Islam yang mereka belum tahu.Generasi penerus perjuangan Nabi Muhammad saw. adalah generasi yang dipilih oleh Allah untuk dfahamkan ilmu Agama Islam, rajin beribadahdan termasuk sepertiga golongan yang masuk surge tanpa hitungan/ hisab.

Untuk dapat mewujudkan generasi penerus perjuangan Nabi ini diperlukan guru Agama Islam yang professional adalah guru yang mampu mendidik muridnya menjadi generasi generasi penerus perjuangan Nabi. Juga diperlukan kemampuan guru menggunakan metode pembelajaran yang bervariasi, strategi pembelajaran yang produktif dan media Pendidikan modern.Diperlukan juga penyediaan sarana prasarana yang menadai yang dapat menunjang tguru dalam merlaksanakan proses balajar mengajar dengan Baik dan menarik minat siswa. Materi pembelajaran meliputi Aqidah/ Tauhid, Fiqih / Ibadah, Akhlak Al Qur an Hadits dan Tasawuf. Semuanya ini dalam rangka mencapai tujuan Pendidikan Agama Islam, yaitu mencetak muslim sejati berpengetahuan luas, nilai, sikap , tingkah laku sesuai dengan tuntutan syariat Islam, bermanfaat bagi mesyarakat, bangsa, negara dan agama yang mendapat ridlo Allah. Dan inilah generasi penerus perjuangan Nabi Muhammad saw. 


\section{DAFTAR PUSTAKA}

A, Winastiti, (2016), Generasi Milenial dan Karekteristiknya, CNN Indonesia.https//student.cnnindonesia.com.

al ‘Asqolani, Ibnu Hajar. Bulughul Maram, Makkah: al Haramain. 1378 H.

al Qoyyim, Ibnu qo'idah Fiqhiyah, Surabaya: al Hidayah, 2000.

Ali, Mohammad Daud. Pendidikan Agama Islam, Jakarta: Raja Grafindo Persada, 1998.

Bukhari, Imam. Shahih BukhariJilid I, Beirut: Dar al Kutub al Ilmiyah, 2000.

Chalim, Asep Saifuddin. Model Pendidikan dalam mengatasi Problema Masa Kini dan akan datang. Surabaya: UIN Sunan Ampel, 2019.

Dawud, Imam Abu Sunan Abu Dawud, 605.

DepDikNas, Baltbang. Kurikulum Berbasis Kompetensi, Ringkasan KBM, Jakarta: balitbang@cbn,net,id,2002.

Imron, Ali. Balajar dan Pembelajaran. Jakarta: Pusaka Jaya, 2000.

Kurniawati, Rinandiyana, dan Kurniawan, (2017), Analisis Factor-faktor yang Mempengaruhi Keputusan Pembelian oleh Generasi Milenial,Jurnal Ekonomi Manajemen. Volume 3, nomor 1.

Muslim,Imam Shahih Muslim, Beirut: Dar al Kutub, 2002

Nurhadi, Pendekatan Kontekstual (Contextual Teaching and Lerning/ CTL), Malang:Universitas Negeri Malang, 2004.

Panjaitan dan Prasetya, (2017), Pengaruh Sosial Media Terhadap Produktivitas Kerja Generasi Millenial, Jurnal Administrasi Bisnis,Volume 48, Nomor 1.

Syah, Muhibbin. Psychologi Pendidikan dengan Pendekatan Baru, Bandung: PT. Remaja Rosdakarya, 2000.

Thoha, Chabib dan Abdul Mu'ti, PBM PAI di Sekolah Eksistensi dan Proses Belajar Mengajar Pendidikan Agama Islam, Bandung: Pustaka Pelajar,1998.

Ya'cub, Mihmidaty. Efektivitas Penerapan Contextual Teaching and Learning di Pondok Pesantren Hidayatullah, Surabaya: UIN Sunan Ampel Pres, 2014. 
Mihmidaty Ya'cub

Pendidikan Masa Kini Untuk Generasi...

Zuhairini, et.al. Metodik Khusus Pendidikan Agama, Malang: Biro Ilmiyah Fakultas Tarbiyah IAIN Sunan Ampel, 1983 